\title{
Rosmarinic Acid-Human Pharmacokinetics and Health Benefits
}

\author{
Authors \\ Maja Hitl ${ }^{\mathbb{D}}$, Nebojša Kladar ${ }^{\mathbb{(}}$, Neda Gavarić, Biljana Božin \\ Affiliation \\ Department of Pharmacy, Faculty of Medicine, \\ University of Novi Sad, Novi Sad, Serbia \\ Key words \\ rosmarinic acid, human, pharmacokinetics, health benefits, \\ safety \\ received \\ May 10, 2020 \\ accepted after revision \\ October 30, 2020 \\ published online \\ December 7, 2020 \\ Bibliography \\ Planta Med 2021; 87: 273-282 \\ DOI $10.1055 / a-1301-8648$ \\ ISSN 0032-0943 \\ (c) 2020. Thieme. All rights reserved. \\ Georg Thieme Verlag KG, Rüdigerstraße 14, \\ 70469 Stuttgart, Germany \\ Correspondence \\ Maja Hitl, MPharm \\ Teaching Assistant \\ Department of Pharmacy, Faculty of Medicine, \\ University of Novi Sad \\ Hajduk Veljkova 3, 21000 Novi Sad, Serbia \\ Phone: + 38121422760 , Fax: + 38121422760 \\ maja.bekut@mf.uns.ac.rs \\ Supplementary material is available under \\ https://doi.org/10.1055/a-1301-8648
}

\begin{abstract}
Rosmarinic acid is a phenolic compound commonly found in the Lamiaceae (Labiateae) plant species. It is considered responsible for a wide spectrum of biological and pharmacological activities of plants containing this compound. The aim of the current review is to present the fate of rosmarinic acid inside the human body, explained through pharmacokinetic steps and to briefly present the health benefits of RA. Pharmacokinetics was at first studied in animal models, but several studies were conducted in humans as well. This compound can be applied topically, pulmonary, intranasally, and via intravenous infusion. However, peroral application is the main route of entry into the human body. Presumably, it is mainly metabolized by the gut microflora, providing simple, more easily absorbed phenolic units. Inside the body, the rosmarinic acid molecule undergoes structural changes, as well as conjugation reactions. Renal excretion represents the main path of elimination. Previously conducted studies reported no serious adverse effects of herbal remedies containing RA, as well as their positive effects on human health. In addition to in vitro studies, clinical investigations suggested its benefits in dermatological, allergic, and osteoarthritic disorders, as well as for improving cognitive performance and in metabolic syndrome treatment. Future studies should investigate the kinetics during long-term application in patients who would have potential benefits from RA usage. Pharmaceutical formulations designed to prevent the fast metabolism of RA and allow its penetration into other compartments of the human body are also interesting topics for future research.
\end{abstract}

acid originating from amino acids L-phenylalanine and L-tyrosine, respectively ( $\bullet$ Fig. 1) [4].

Although the structure of the compound was not known until 1958, early researchers suggested the presence of a compound responsible for the beneficial effects of some herbs [2].The aim of this review is to represent the fate of RA in the human body, explained through the pharmacokinetic steps, and to briefly present some of the health benefits of RA.

\section{RA in Herbal Material}

Chemical profiling studies often detect RA in extracts obtained from various plants. The mediums used for obtaining these extracts vary widely, although it appears that alcoholic extracts are the most frequent; extraction is usually performed by cold macer- 
ation or heat-assisted techniques, while the extraction time ranges from 10 min to 30 days. Further analysis of the extracts is commonly carried out by the means of HPLC coupled with various detectors $[5,6]$. Researchers found that the content of RA varies between the species of the same genus, subspecies of the same species, samples collected in different seasons of the year, etc. [5]. However, the amount of RA can be used as a parameter for estimating herbal drug quality (e.g., lemon balm [Melissa officinalis, Lamiaceae] and rosemary leaves should contain $\geq 4 \%$ and $\geq 3 \%$ of total hydroxycinnamic acids expressed as RA, respectively) [7, 8]. Table 1S in Supporting information presents data on medicinal plants reported to contain RA. As the data suggests, the majority of the reported medicinal plants (especially those of the Nepetoideae subfamily of Lamiaceae family) represent a valid herbal source of this compound. However, no guarantee of high amount of RA can be given, as the reported amount of RA varied widely in some of the investigated species, and in some cases, even the absence of RA was reported. Thus, the first step in investigating herbal material containing RA should be the precise quantification of the compound before any type of in vitro or clinical investigation is conducted.

\section{Routes of Administration}

As previously stated, RA is a compound that can be found in some of the most frequently used spices and aromatic representatives of the Lamiaceae family; thus, the peroral intake of RA is of special interest. These plants can be ingested in dried, often pulverized form that is added to food or used as spices. Aside from this, many medicinal plants of this kind are consumed as tea infusions $[9,10]$. This compound can also be applied topically, which is consistent with the traditional use of lemon balm as a topical antiviral agent $[7,11,12]$. The application of proper pharmaceutical formulations intended to provide local effects could find its place in the treatment of various dermatological conditions. Some of them have already been attempted. A niosomal gel with $3 \%$ RA was tested in a simulated acne study performed on mice. Potent antibacterial and anti-inflammatory effects were demonstrated through the reduction of bacterial (Propionibacterium acnes) multiplication rate and inflammation rate. Additionally, the niosomal gel was demonstrated to be more effective than RA in the forms of solution or plain gel [13]. It is also suggested that topical application could find its place in the prevention of skin aging [14,15], as ex vivo studies of ethosomes and liposomes containing RA showed an inhibitory effect against elastase and collagenase, the enzymes responsible for the loss of skin elasticity [15]. Intranasal application of solid lipid nanoparticles containing a $12 \mathrm{mg}$ dose of pure RA gave promising results in rats as a noninvasive route of administration for potential targeted treatment of central nervous system diseases such as Huntington's disease [16]. Another study in rats demonstrated the possibility of a pulmonary application. An extract of Danshen (biological source Salvia miltiorrhiza), traditional Chinese medicine, containing RA was applied using microspray, and it was demonstrated that this type of application resulted in rapid absorption. Pulmonary application is of great significance in various diseases affecting the respiratory system, especially in conditions that require an immediate drug effect; thus, the possi-

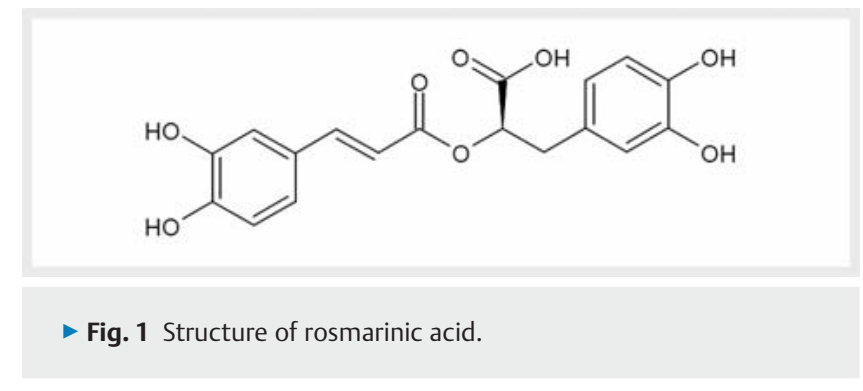

bility of RA application in such a manner requires further investigations [17]. Ocular application of the drug is of importance in various eye diseases. An in vitro test performed on cell lines of the human retina and human cornea showed that the application of chitosan-based nanoparticles containing RA or organic-cultivated sage (Salvia officinalis) and savory (Satureja montana) extracts rich in RA exhibits promising potential and requires further research [18]. Another research study investigated an intravenous application of compounds isolated from Danshen-RA, lithospermic acid and lithospermic acid B. A mixture of these compounds was dissolved in a hypertonic solution of glucose and applied in the form of slow intravenous infusion. The study confirmed that this type of application is possible, effective, and safe, which is consistent with its use in traditional Chinese medicine for certain cardiac and pulmonary events [19].

\section{Investigation of RA's Pharmacokinetics}

The initial investigations of RA's pharmacokinetics were conducted on animal models, primarily in rats and mice. These data gave starting points for human studies, such as for the main metabolites, pharmacokinetic parameters, and routes of elimination, although it was later discovered that the pharmacokinetics of RA in animals and humans is somewhat different [20]. The data given in further text originate from human studies, unless otherwise stated. The scheme of human RA pharmacokinetics is presented in $>$ Fig. 2, and the explanation of the specific segments is provided in further text.

\section{Absorption}

Lipinski's rule ("the rule of 5") is often used to estimate whether a compound is "drug-like" and a potential candidate for peroral application [21]. The in silico calculated values of the parameters determined according to this rule are given in $>$ Table 1 [22].

Since the compound does not violate a single rule, promising bioavailability is expected after peroral application. According to these in silico calculations, the absorption of RA is 59.14\% [22]. However, in vitro, as well as in vivo investigations of RA absorption, suggest that its intestinal permeability is much lower, approximately $1 \%$ of the applied dose $[23,24]$, and that the absorption of the compound occurs via enterocytes by paracellular transport in tight junctions [25].

Absorption through the skin is also investigated as RA-rich extracts can be found in topical formulations. An ex vivo study conducted on intact human skin has shown that RA accumulates in 


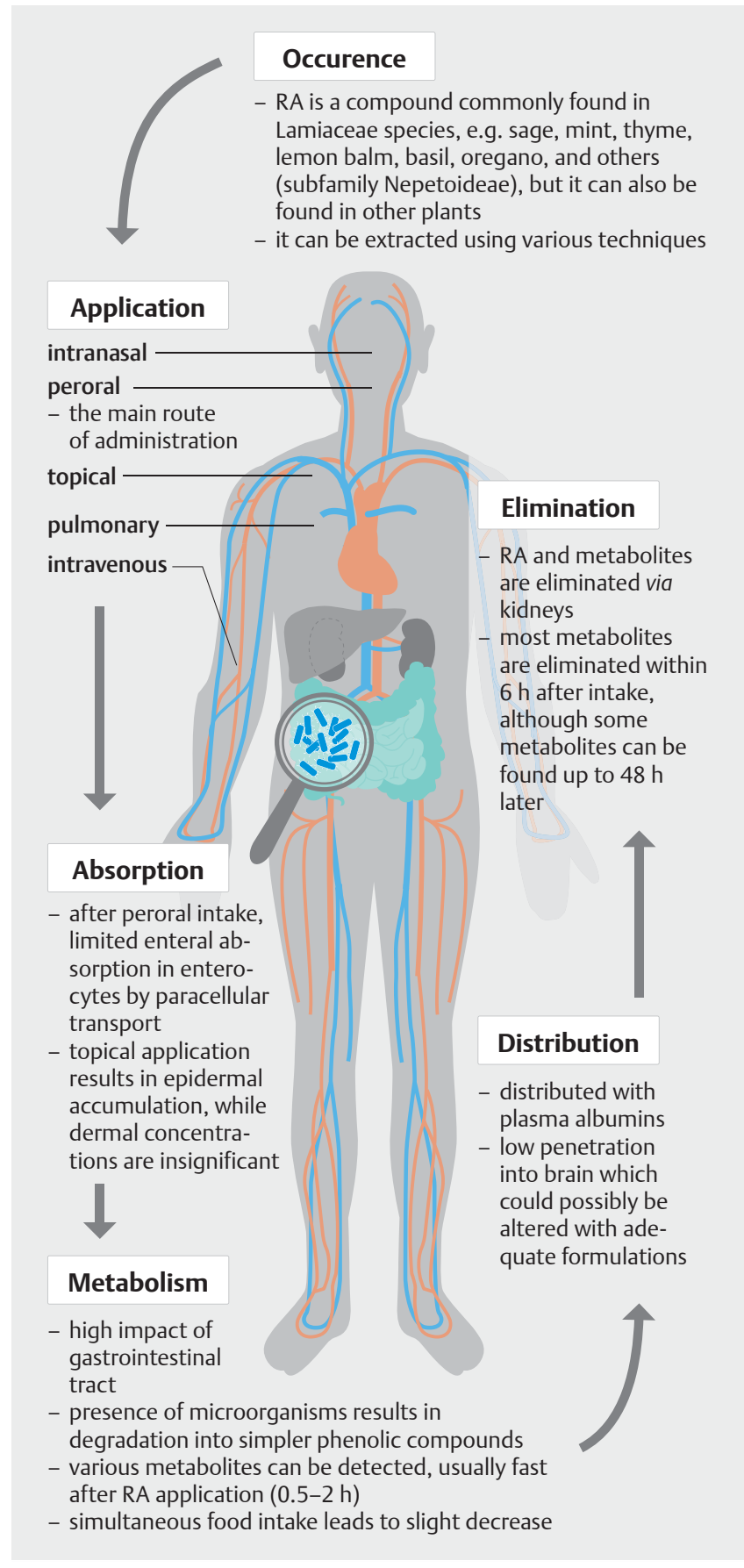

- Fig. 2 A scheme of human pharmacokinetics of rosmarinic acid. Source: Christine Lackner

the epidermis, while the penetration into the hydrophilic dermis can practically be disregarded. Higher amounts of RA were detected when olive oil was used in the formulation, possibly due to the presence of natural penetration enhancers [26].
- Table 1 The rule of Lipinski and values calculated for rosmarinic acid.

\begin{tabular}{|l|l|}
\hline Lipinski's rule & $\begin{array}{l}\text { Calculation for } \\
\text { rosmarinic acid }\end{array}$ \\
\hline molecular weight $\leq 500$ Daltons & 360.32 \\
\hline $\begin{array}{l}\text { log P (logarithm of octanol-water partition } \\
\text { coefficient) } \leq 5\end{array}$ & 1.626 \\
\hline hydrogen bond donors $\leq 5$ & 5 \\
\hline hydrogen bond acceptors $\leq 10$ & 8 \\
\hline number of violations for rosmarinic acid & 0 \\
\hline
\end{tabular}

\section{Distribution}

Since RA is relatively insoluble in water [27], it can be expected that the compound is distributed throughout the circulatory system by plasma proteins. An in vitro study of the interaction between RA and the human serum albumin revealed that RA is probably carried by these proteins. A moderately strong bond is formed through hydrophobic interactions between these proteins and RA $[28,29]$. Studies conducted on human volunteers lack data on the body distribution of RA; however, some data from animal studies are available. The topical application of RA in rats resulted in distribution into blood, skin, bones, and muscles; after intravenous application, the compound was detected also in soft tissues of internal organs such as the spleen, liver, lungs, and heart [20]. Similarly, after intraperitoneal application in mice, the highest amount of RA was found in the kidneys, followed by the lungs, spleen, and liver [30]. Another interesting aspect of RA's distribution is the concentration achieved in the brain. The data suggest that the hematoencephalic barrier effectively prevents penetration into the central nervous system $[23,30]$. As previously suggested, a targeted approach (intranasally) using a specific pharmaceutical formulation results not only in passing the blood-brain barrier and achieving higher concentrations in the brain but also in reducing the amount of RA that is distributed to be metabolized [16]. Some of the concentrations/amount of RA detected in animal tissues are presented in $\boldsymbol{\vee}$ Table $\mathbf{2}$.

\section{Metabolism}

\section{Impact of the gastrointestinal tract}

The environment of the human gastrointestinal tract (GIT) can greatly affect the content of ingested phenolic compounds [25]. Throughout the GIT, pH values vary greatly. The highly acidic gastric environment can lead up to $\geq 50 \%$ reduction of RA's concentration; in contrast, alkaline intestinal digestion was demonstrated to have a lower impact. Pure RA was found to be relatively stable in various $\mathrm{pH}$ mediums, while the extracts containing RA showed a reduction of RA content [31,32], up to $99 \%$ in the case of thyme [31]. An in vitro study comparing 2 formulations, divided powder and hard gelatine capsules, demonstrated that capsules should be the preferred form of intake for oregano (Origanum vul- 
- Table 2 Amount/concentration of rosmarinic acid (RA) detected in organs of laboratory rats after compound application.

\begin{tabular}{|c|c|c|c|c|}
\hline $\begin{array}{l}\text { Animal } \\
\text { model }\end{array}$ & $\begin{array}{l}\text { Route of } \\
\text { administration }\end{array}$ & Dose of RA & $\begin{array}{l}\text { Detected amount/concentration } \\
\text { in some of organs }\end{array}$ & Reference \\
\hline \multirow[t]{3}{*}{ rat } & intranasal & $\begin{array}{l}12 \mathrm{mg} \text { (in a form of solid lipid } \\
\text { nanoparticles) }\end{array}$ & brain: $5.69 \mu \mathrm{g}$ & [16] \\
\hline & intravenous & $\begin{array}{l}\text { Extract of Salvia milthiorrhiza contain- } \\
\text { ing RA was applied in dose of } 56 \mathrm{mg} / \\
\mathrm{kg} \text { (concentration of RA in extract was } \\
\text { not determined). }\end{array}$ & $\begin{array}{l}\text { heart: } 149.91 \mathrm{ng} / \mathrm{mL} \\
\text { liver: } 175.61 \mathrm{ng} / \mathrm{mL} \\
\text { spleen: } 68.46 \mathrm{ng} / \mathrm{mL} \\
\text { lung: } 198.04 \mathrm{ng} / \mathrm{mL} \\
\text { kidney: } 9353.9 \mathrm{ng} / \mathrm{mL} \\
\text { brain: } 5.12 \mathrm{ng} / \mathrm{mL}\end{array}$ & [70] \\
\hline & intravenous & $\begin{array}{l}\text { Extract of Salvia milthiorrhiza contain- } \\
\text { ing } \geq 10.1 \% \text { RA was applied in dose of } \\
60 \mathrm{mg} / \mathrm{kg} \text {. }\end{array}$ & $\begin{array}{l}\text { heart: } 1.08 \mu \mathrm{g} / \mathrm{g} \\
\text { liver: } 0.29 \mu \mathrm{g} / \mathrm{g} \\
\text { spleen: } 0.07 \mu \mathrm{g} / \mathrm{g} \\
\text { lung: } 3 \mu \mathrm{g} / \mathrm{g} \\
\text { kidney: } 43.65 \mu \mathrm{g} / \mathrm{g} \\
\text { brain: } 0.06 \mu \mathrm{g} / \mathrm{g}\end{array}$ & [71] \\
\hline
\end{tabular}

gare), as they protect the present RA from the process of gastrointestinal digestion [33].

The gut microbiota represents an important organ with a significant role in the metabolism of nutrients, drugs, and other xenobiotics [34]. In general, a major part (up to 95\%) of the ingested complex phenolic compounds cannot be absorbed in the intestine. However, these compounds are further metabolised by the intestinal microflora $[20,25]$. In most of the cases, complex phenolic compounds are at first degraded into simpler units (e.g., phenolic acids), in order to be absorbed in the digestive tract [35]. Similarly, the degradation of RA into 2 phenolic acids would allow their further absorption $[20,36]$, and it was demonstrated in vitro in Caco-2 cell culture that microbial esterases were responsible for cleaving the bond of the RA molecule rather than the esterase present in the mucosa of the intestinal tract [36].

Some of the studies investigated the effects of gut microbes on the RA content. In one study, an in vitro process of colonic fermentation of a rosemary extract containing RA by using microorganisms from rat feces was performed. It was demonstrated that $14 \%$ of the RA content is lost through this process [32]. In contrast, another study stated that an even higher percentage of RA (>90\%) can be hydrolyzed in vitro by probiotic Lactobacillus strains in optimal conditions [37]. Finally, a study using human fecal samples for in vitro fermentation of phenolic compounds present in thyme (Thymus vulgaris) was performed. A fast decline in RA concentration had occurred during the first $6 \mathrm{~h}$ of fermentation, and it was reduced to trace levels after $12 \mathrm{~h}$. The same research also tested the amount of RA present in feces of human volunteers consuming thyme-enriched olive oil over a period of $3 \mathrm{wk}$. This analysis showed no RA presence, thus confirming a high level of degradation in the gastrointestinal tract [38].

\section{Metabolic pathways}

Studies conducted in rats provided starting data about metabolites that are likely to appear in plasma and urine [39-41]. Later research has shown that metabolites detected in human subjects are predominantly the same, although the main metabolic path- ways are quantitatively somewhat different. Some of the in vitro obtained data in Caco- 2 and Hep G2 cell cultures, as models of the small intestine and liver respectively, demonstrated that rosemary extracts containing RA, as well as the pure compound, can be partially absorbed and metabolized in the previously mentioned cells [42]. The metabolites detected in this study [42], as well as in the study testing the metabolism of RA in human liver microsomes [43], pointed out the most probable metabolites of RA, which were also confirmed in studies on human volunteers. However, the metabolites are most likely the result of both microbial and hepato-intestinal enzymatic reactions.

Shortly after peroral or intravenous application, RA is detected in blood in its free form ( $\vee$ Table 3 ).

As seen in $>$ Table 2 , the concurrent consumption of food and RA leads to a slight decrease of RA concentration in plasma and prolongs the time necessary for achieving the maximum concentration. The compound can also be detected in the form of a sulphate, glucuronide, and/or sulphoglucuronide [44]. An in vitro study in human liver microsomes suggested that glucuronidation of RA is the main metabolic pathway [43]. When comparing the 2 doses ( 250 and $500 \mathrm{mg}$ of RA), it was evident that an increase of dosage was followed by an increase of free RA concentration, while the concentration of conjugated forms increased insignificantly. All of this suggests that conjugational processes are characterized by saturation kinetics [45].

Simultaneously with the previously mentioned processes, a conjugation reaction of RA methoxylation also occurs, so it is possible to detect methyl conjugate (met-RA) in blood. This metabolic reaction is slower, so this compound's maximum concentration is achieved $2 \mathrm{~h}$ after ingestion $(0.65 \pm 0.07 \mu \mathrm{mol} / \mathrm{L}$, after a dose of $200 \mathrm{mg}$ of RA) [44]. Interestingly, a study following a 30-day intake of spearmint (Mentha spicata) extract rich in RA detected met-RA glucuronide as the main marker metabolite of RA's subchronic consumption [46].

The metabolism of the caffeic acid segment of RA structure was further studied, revealing several metabolites resulting from various reactions. Ferulic acid was detected in blood [45]. This 
- Table 3 Concentrations of rosmarinic acid, determined in human studies.

\begin{tabular}{|c|c|c|c|c|c|}
\hline $\begin{array}{l}\text { The route of } \\
\text { application }\end{array}$ & $\begin{array}{l}\text { Number of } \\
\text { participants }\end{array}$ & Dose of RA & $\begin{array}{l}\text { Maximum of detected RA con- } \\
\text { centration }\left(C_{\max }\right) \text { in plasma }\end{array}$ & $\begin{array}{l}\text { Time of } C_{\max } \text { deter- } \\
\text { mination }\left(T_{\max }\right)\end{array}$ & Reference \\
\hline \multirow[t]{4}{*}{ Peroral } & $\begin{array}{l}6 \text { male healthy } \\
\text { volunteers }\end{array}$ & $200 \mathrm{mg}$ & $1.15 \pm 0.28 \mu \mathrm{mol} / \mathrm{L}$ & $0.5 \mathrm{~h}$ & {$[44]$} \\
\hline & \multirow{3}{*}{$\begin{array}{l}6 \text { healthy } \\
\text { volunteers }\end{array}$} & 250 mg (fasted) & $72.22 \pm 12.01 \mathrm{nmol} / \mathrm{L}$ & $1 \mathrm{~h}$ & [45] \\
\hline & & $500 \mathrm{mg}$ (fasted) & $162.20 \pm 40.20 \mathrm{nmol} / \mathrm{L}$ & $1 \mathrm{~h}$ & {$[45]$} \\
\hline & & $500 \mathrm{mg}$ (fed) & $142.20 \pm 45.20 \mathrm{nmol} / \mathrm{L}$ & $3 \mathrm{~h}$ & {$[45]$} \\
\hline \multirow[t]{2}{*}{ Intravenous } & \multirow{2}{*}{$\begin{array}{l}6 \text { male and } \\
6 \text { female healthy } \\
\text { volunteers }\end{array}$} & $\begin{array}{l}\geq 4.5 \% \mathrm{RA} \text { in } 100 \mathrm{mg} \\
\text { of mixture }\end{array}$ & $174 \pm 61 \mathrm{ng} / \mathrm{mL}$ & $0.47 \mathrm{~h}$ & [19] \\
\hline & & $\begin{array}{l}\geq 4.5 \% \mathrm{RA} \text { in } 200 \mathrm{mg} \\
\text { of mixture }\end{array}$ & $308 \pm 77 \mathrm{ng} / \mathrm{mL}$ & $0.54 \mathrm{~h}$ & [19] \\
\hline
\end{tabular}

compound is a product of RA catabolism via caffeic acid, while further sulphatation and methoxylation of the hydroxyl group may occur [44]. Similar to the conjugation of RA, this reaction is fast (detection $0.5 \mathrm{~h}$ after ingestion of $200 \mathrm{mg}$ of RA showed $0.36 \pm 0.17 \mu \mathrm{mol} / \mathrm{L}$ ) [45]. Another catabolic product was detected in human plasma: 2,4,5-trimetoxycinnamic acid. This compound is also metabolized through caffeic acid from RA, but it undergoes reactions of hydroxylation, dihydroxylation, and methoxylation [40]. Also, the metabolism of the caffeic acid segment in human subjects can lead to the formation of $m$-coumaric acid and its conjugates [44]. An in vitro study also presumed that 2-(3',4'-dihydroxyphenyl)propionic acid is an important intermediary compound [38]. Specifically, the first metabolic pathway leads to the formation of phenylacetic acid (as detected in an in vitro study of RA fermentation with human fecal samples) [38], while the second leads to the formation of protocatechuic acid (as detected in human subjects consuming Origanum onites extract containing RA) [47]. The latter compound can also be further metabolized into 2 compounds, $p$-hydroxybenzoic acid or vanillic acid (and its sulphate conjugate) $[46,47]$.

The complete metabolism of RA is presented in > Fig. 3 .

\section{Elimination}

Initial investigations conducted in rats had detected an increased concentration of RA in kidneys, suggesting renal elimination; some metabolites were also found in the rats' bile [20,48]. After peroral application in humans, free and conjugated forms of RA and met-RA were detected in urine of healthy volunteers. Caffeic, ferulic, 2,4,5-trimetoxycinnamic acid, $m$-coumaric acid, vanillic and $p$-hydroxybenzoic acid, all in free and conjugated forms were also found, but in lower concentrations $[40,44,47]$. In the same manner as the metabolism, the elimination is also rapid. Specifically, the majority of the metabolites are eliminated within $6 \mathrm{~h}$ after intake, while it is rather hard to detect traces of other metabolites after 24-48 h [44]. The previously mentioned research describing intravenous application is also consistent with this data. Namely, a steady state is achieved with continuous infusion, but after the infusion termination, a fast decrease of the concentra- tions of RA and its metabolites in blood and their increase in urine is recorded [19].

\section{Health Benefits and Efficacy}

Numerous in vitro studies were conducted in order to show the beneficial effects of RA. Some of its confirmed activities include antioxidative, antibacterial (against both gram-positive and gram-negative bacteria), antiviral, astringent, analgesic, anti-inflammatory (mediated by the inhibition of lipoxygenase, cyclooxygenase, the complementary cascade and pro-inflammatory mediators), antihyperglycemic (mediated by the pancreatic amylase and glucosidase inhibition and by sensitizing glucose transporters), hepatoprotective (mediated by the inhibition of fibrosis, and scavenging of different reactive radical species), immunomodulatory (mediated by the stimulation of the cell immune system), anticancer (against various types of carcinoma, including colorectal, pancreatic, breast, lung, ovarian, melanoma, and several others), cardioprotective, neuroprotective properties, and many others [5, 20,49-52]. Most of these studies are performed with a pure compound or with extracts containing RA. As previously pointed out, the quantification of RA applied in the studies is of great importance in order to evaluate the validity of the applied preparation. However, bearing in mind the previously presented pharmacokinetics of the compound (especially its limited peroral absorption, fast metabolism, and limited distribution to the central nervous system), large differences between the results obtained in vitro and the potential in vivo effects can be expected. This is primarily due to the presumed discrepancies between the tested concentrations in laboratory/preclinical settings and the presumably highly reduced concentration that would be detected at the site of the pharmacological effect.

Apart from preclinical investigations, several clinical studies tested RA-containing extracts and products in patients with different medical conditions in order to evaluate the "real" health benefits of RA. One study demonstrated positive co-therapeutic effects of spearmint tea containing a high percentage of RA in patients with knee osteoarthritis. The patients were consuming approximately $280 \mathrm{mg}$ of RA daily during $16 \mathrm{wk}$, in the form of a tea 


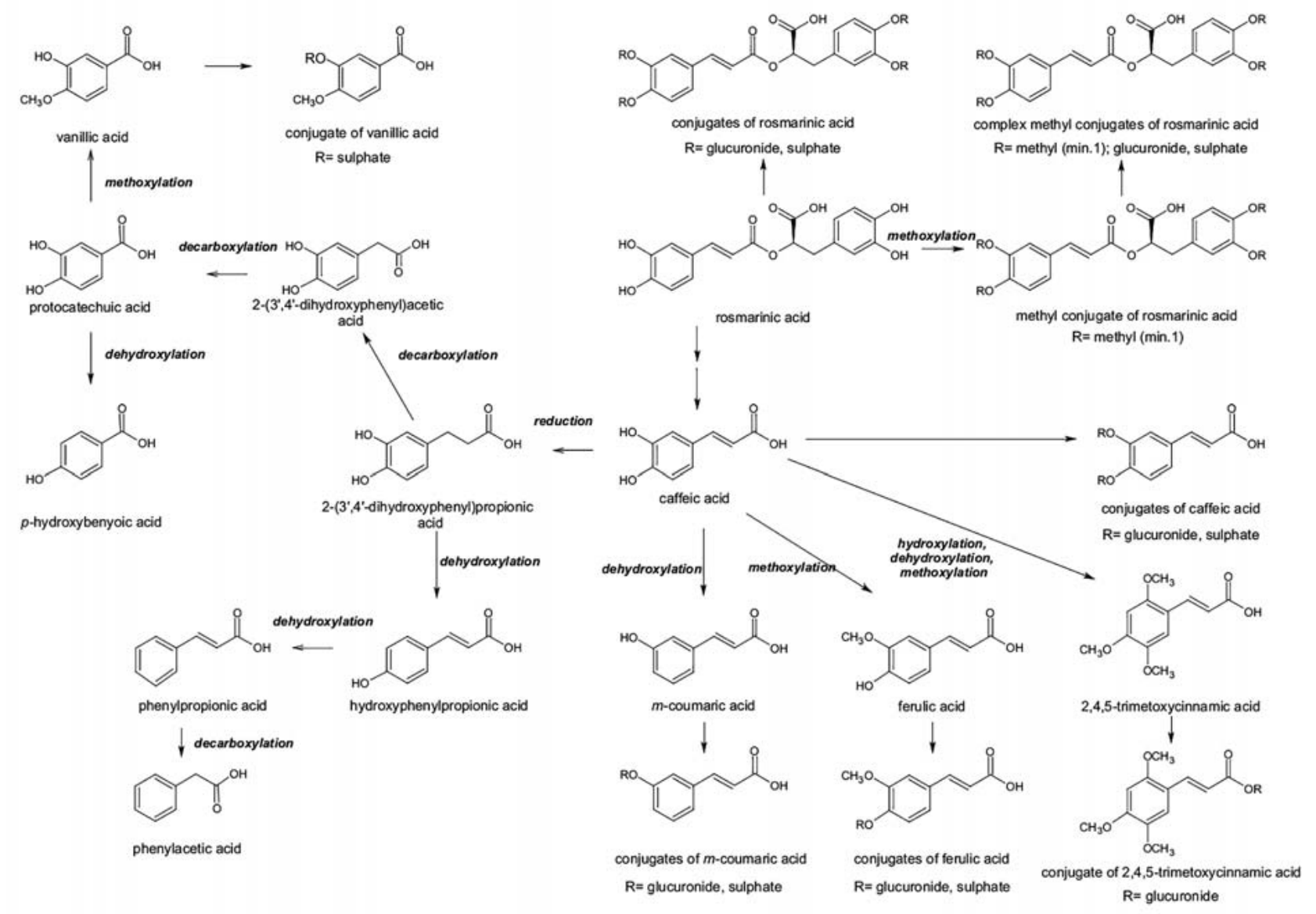

- Fig. 3 Presumed metabolism of rosmarinic acid, based on metabolites detected in human studies.

beverage. The positive effect was primarily noted through pain reduction, as the patients significantly reduced the number of analgesics used for the symptomatic treatment of the underlying condition [53]. Another study using a spearmint extract with a high content of RA ( $900 \mathrm{mg}$ of extract with $\geq 14.5 \%$ of RA, during 90 days) tested this herbal preparation as a potential nootropic herbal remedy, concluding that it effectively improves reactive agility in young, healthy individuals, which is potentially important in athletic performances requiring stationary and multi-directional activity [54]. The same herbal preparation of RA in 2 doses (600 mg or $900 \mathrm{mg}$ ) applied to the older population over the course of 90 days was shown to improve their cognitive performance (often affected by the aging process), as well as lead to sleep induction and general mood improvement, especially when applied in a higher dosage [55]. Another study tested $900 \mathrm{mg}$ of spearmint extract containing $15 \%$ of RA during 30 days, also in an older population. The results suggested that cognitive performance, including attention, concentration, and planning was improved due to the RA supplementation [46]. Improved cognitive performance (better working memory results) and the anti-stress (anxiolytic) effects of RA-rich food (an ice-tea type of beverage and yoghurt containing $0.3 \mathrm{~g}$ or $0.6 \mathrm{~g}$ of lemon balm extract with $>6 \%$ of RA) were confirmed in the young population [56]. A cream containing $0.3 \%$ of RA was used in a 2 -mo study in patients with moderate atopic dermatitis; it was shown that the RA cream successfully reduced several problems, including erythema, crusting, edema, and local pruritus [57]. Another beneficial effect is recorded in application in patients suffering from seasonal allergic rhinoconjunctivitis. The application of $200 \mathrm{mg}$ of RA during 21 days resulted in a decrease of symptoms (itchy nose and eyes and watery eyes). The reduced number of neutrophils and eosinophils in nasal lavage fluid suggests that RA reduced inflammation mediated by these cells, presumably through the inhibition of $\mathrm{IgE}$ production $[58,59]$. Some studies suggested a potential role of RA-containing extracts as co-therapeutics in metabolic syndrome therapy [60]. Lemon balm extract showed positive effects primarily expressed through hypolipemic activity. Namely, a reduction of serum triglycerides [61-63], cholesterol [61,63], and biomarkers of oxidative stress [63], as well as an increase of high-density lipoproteins $[63,64]$ were recorded in patients with diabetes type $2[62,64]$, in patients with chronic stabile angina [63], and in workers professionally exposed to agents triggering high levels of oxidative stress products [61]. All of the data suggest that potent in vitro antioxidant activity appears to be effective in vivo. Furthermore, some data from animal studies also point out that hypolipidemic activity is mediated through an increased synthesis of bile 
acids, increased oxidation of fatty acids, decreased synthesis of new fatty acids, and decreased synthesis of cholesterol [65]. All of these studies suggest that RA and herbal extracts containing it possess high and diverse potential for application in various groups of patients, and that RA could find its place as an adjuvant to certain conventional drugs.

\section{Safety}

The previously mentioned studies examining human pharmacokinetics of RA were conducted using a single dose application in a small number of healthy volunteers $[19,44,45]$. At the same time, the safety of RA was investigated through physical examination, the appearance of adverse effects, the evaluation of biochemical blood parameters (blood count, biochemical parameters of liver and kidney function) $[19,45]$, and cardiac function (electrocardiogram) [19]. No side effects of single dose application in humans were detected.

Other studies investigating the efficacy and health benefits of herbal extracts containing RA in general reported a lack of serious adverse effects $[54-56,58,59]$. Some of the recorded complaints in groups that had received RA included headaches, constipation, diarrhea [53], worsening of cystic acne, and an oily scalp [55], etc. However, it is important to point out that some complaints were also recorded in placebo groups, including dry mouth, itchy skin, and denture staining [53]. A study that tested a 2-mo application of an RA-containing cream reported no local adverse effects on the skin affected by atopic dermatitis [57].

\section{Future Studies and Considerations}

Current data lack information on several aspects of RA applications. As previously presented, available pharmacokinetic studies were conducted in a limited number of volunteers, and evaluated single-dose applications. The presented clinical trials suggest an effectiveness of RA-containing preparations after consumption over longer periods of time. Therefore, pharmacokinetic studies after chronic application of this secondary metabolite would possibly contribute to better understanding of metabolic pathways and the pharmacological potential and could explain the mechanism of activity. While one study gave some data on sub-chronic consumption of RA (30 days) [46], it can be expected that positive pharmacological effects would require a longer period of time. Establishing the longest safety period of RA's usage is also of interest.

Applied doses varied greatly in studies related to the application of RA-based preparations. From a potential therapeutic point of view, it would be useful to determine the adequate dose and dosage regimen for various conditions being treated. The extrapolation of data obtained in preclinical studies performed on rodents allowed the calculation of the upper tolerable daily intake of RA in humans of $500 \mathrm{mg}$ [45]. Another aspect of interest would be to determine $C_{\text {trough }}$-the lowest concentration that a drug reaches before the next dose is administered-as only the adequate values of $C_{\text {trough }}$ over a certain period of time will result in beneficial effects.
Secondly, current data suggest that modified pharmaceutical formulations are required for RA application. As peroral application results in limited absorption, fast metabolism, and fast elimination, it would be necessary to rationalize a formulation that would overcome these limiting factors. An adequate formulation is also needed in order to protect RA from being degraded by the gastrointestinal tract. This could possibly be achieved by using solid lipid nanoparticles $[66,67]$ or liposomes [68]. Other routes of administration would also require formulations improving delivery to targeted locations (e.g., brain or eye), where RA would be of potential benefit in patients $[16,18]$. Previous studies demonstrated the importance of a vehicle used for topical drug formulation since inadequately chosen excipients could decrease the RA release from formulations $[15,26]$.

Finally, in order to determine the true benefits of RA use, studies should be performed in patients with different diseases and conditions, primarily with prominent pro-oxidant and pro-inflammatory mediators. The mentioned studies that confirmed the efficacy and health benefits reported positive pharmacological effects in patients primarily associated with antioxidant, antiallergic, and hypolipidemic activities [61,63,64,69]. However, further studies are required in order to elucidate the potential mechanism(s) of these recorded activities.

\section{Conclusion}

RA is a compound with promising potential for further clinical studies. Additional data on its pharmacokinetics are necessary in order to elucidate its position in the prevention and co-therapy of various pathological conditions. Fast processes of its metabolism, distribution, and elimination, as well as its limited peroral absorption suggest that there is a need for adequate pharmaceutical formulation development that would allow targeted and extended activity.

\section{Methodology}

Bearing in mind that RA is a relatively well-known compound of natural origin, this review focused on the less investigated aspects of its pharmacokinetics in the human body and clinical effectiveness. The comprehensive search for relevant scientific articles was conducted through PubMed, Scopus, ScienceDirect, and Google Scholar. The search was conducted using a combination of various key words, including "rosmarinic acid”, “Lamiaceae”, "content”, "pharmacokinetics”, “application”, “administration”, “absorption”, “distribution”, “metabolism”, “microbial”, “fermentation”, "elimination", "health benefit”, "efficacy”, "safety”, "clinical trial”, "human", etc. The retrieved articles were inspected for their content, and focus was given to research articles dealing with studies performed on human subjects. Pharmacokinetic studies on laboratory animals were originally excluded in case a certain topic lacked human data (e.g., as was the case with the Distribution section), data were supplemented from studies conducted on animals. Additionally, references of valid articles were inspected in order to retrieve additional articles. Only articles written in English were included. The search was performed from January to the end 
of July 2020. No limitations were given for years of published articles used for this review.

\section{Supporting Information}

Table 1S contains data on medicinal herbs referred by European Medicines Agency to contain rosmarinic acid, and the data on content of the compound in extracts of these herbs, obtained by various procedures of extraction.

\section{Contributors' Statement}

Data collection: M. Hitl, N. Kladar, B. Božin. Design of the paper: M. Hitl, N. Gavarić, B. Božin. Statistical analysis: not applicable. Analysis and interpretation of the data: M. Hitl, N. Kladar, N. Gavarić. Drafting the manuscript: M. Hitl, N. Kladar, N. Gavarić, B. Božin. Critical revision of the manuscript: N. Kladar, N. Gavarić, B. Božin.

\section{Acknowledgements}

This study was supported by The Ministry of Education, Science and Technological Development, Republic of Serbia (grant number 451-0368/2020-14/200114).

Conflict of Interest

The authors declare that they have no conflict of interest.

\section{References}

[1] Petersen M, Abdullah Y, Benner J, Eberle D, Gehlen K, Hucherig S, Janiak V, Kim KH, Sander M, Weitzel C, Wolters S. Evolution of rosmarinic acid biosynthesis. Phytochemistry 2009; 70: 1663-1679

[2] Petersen M, Simmonds MS. Rosmarinic acid. Phytochemistry 2003; 62: $121-125$

[3] Božin B, Gavrilović M, Kladar N, Rat M, Anačkov G, Gavarić N. Highly invasive alien plant Reynoutria japonica Houtt. represents a novel source for pharmaceutical industry-evidence from phenolic profile and biological activity. J Serb Chem Soc 2017; 82: 803-813

[4] Dewick P. Medicinal natural Products: A biosynthetic Approach. New York: Wiley; 2009

[5] Amoah SK, Sandjo LP, Kratz JM, Biavatti MW. Rosmarinic acid-pharmaceutical and clinical aspects. Planta Med 2016; 82: 388-406

[6] Sik B, Kapcsándi V, Székelyhidi R, Hanczné E, Ajtony Z. Recent advances in the analysis of rosmarinic acid from herbs in the Lamiaceae family. Nat Prod Commun 2019; 14: 1-10

[7] World Health Organization (WHO). WHO Monographs on selected medicinal Plants, Vol. 4. Geneva: World Health Organization; 2009

[8] World Health Organization (WHO). WHO Monographs on selected medicinal Plants, Vol. 2. Geneva: World Health Organization; 2004

[9] Kokkini S, Karousou R, Hanlidou E. Herbs of the Labiatae. In: Cabarello B, Trugo L, Finglas P, eds. Encyclopedia of Food Sciences and Nutrition. London: Elsevier; 2003: 3082-3090

[10] Carović-Stanko K, Petek M, Grdiša M, Pintar J, Bedeković D, Herak Ćustić M, Satović Z. Medicinal plants of the family Lamiaceae as functional foods-a review. Czech J Food Sci 2016; 34: 377-390

[11] Wolbling RH, Leonhardt K. Local therapy of herpes simplex with dried extract from Melissa officinalis. Phytomedicine 1994; 1: 25-31

[12] Koytchev R, Alken RG, Dundarov S. Balm mint extract (Lo-701) for topical treatment of recurring herpes labialis. Phytomedicine 1999; 6: 225230
[13] Budhiraja A, Dhingra G. Development and characterization of a nove antiacne niosomal gel of rosmarinic acid. Drug Deliv 2015; 22: 723-730

[14] Tundis R, Loizzo MR, Bonesi M, Menichini F. Potential role of natural compounds against skin aging. Curr Med Chem 2015; 22: 1515-1538

[15] Yucel C, Seker Karatoprak G, Degim IT. Anti-aging formulation of rosmarinic acid-loaded ethosomes and liposomes. J Microencapsul 2019; 36: $180-191$

[16] Bhatt R, Singh D, Prakash A, Mishra N. Development, characterization and nasal delivery of rosmarinic acid-loaded solid lipid nanoparticles for the effective management of Huntington's disease. Drug Deliv 2015; 22: 931-939

[17] Lu P, Xing Y, Xue Z, Ma Z, Zhang B, Peng H, Zhou QT, Liu H, Liu Z, Li ]. Pharmacokinetics of salvianolic acid B, rosmarinic acid and Danshensu in rat after pulmonary administration of Salvia miltiorrhiza polyphenolic acid solution. Biomed Chromatogr 2019; 33: e4561

[18] da Silva SB, Ferreira D, Pintado M, Sarmento B. Chitosan-based nanoparticles for rosmarinic acid ocular delivery-in vitro tests. Int ] Biol Macromol 2016; 84: 112-120

[19] Jia JY, Lu YL, Li XC, Liu GY, Li S], Liu Y, Liu YM, Yu C, Wang YP. Pharmacokinetics of depside salts from Salvia miltiorrhiza in healthy Chinese volunteers: a randomized, open-label, single-dose study. Curr Ther Res Clin Exp 2010; 71: 260-271

[20] Nunes S, Madureira AR, Campos D, Sarmento B, Gomes AM, Pintado M, Reis F. Therapeutic and nutraceutical potential of rosmarinic acid-cytoprotective properties and pharmacokinetic profile. Crit Rev Food Sci Nutr 2017; 57: 1799-1806

[21] Lipinski CA, Lombardo F, Dominy BW, Feeney PJ. Experimental and computational approaches to estimate solubility and permeability in drug discovery and development settings. Adv Drug Deliv Rev 2001; 46: 3-26

[22] Nath LS, Khan SA, Ahmad A. Computer aided screening of natural products in search of lead molecules for design and development of potent anti-inflammatory agents. Sch Acad J Pharm 2014; 3: 496-503

[23] Hase T, Shishido S, Yamamoto S, Yamashita R, Nukima H, Taira S, Toyoda T, Abe K, Hamaguchi T, Ono K, Noguchi-Shinohara M, Yamada M, Kobayashi S. Rosmarinic acid suppresses Alzheimer's disease development by reducing amyloid beta aggregation by increasing monoamine secretion. Sci Rep 2019; 9: 8711

[24] Konishi Y, Hitomi Y, Yoshida M, Yoshioka E. Pharmacokinetic study of caffeic and rosmarinic acids in rats after oral administration. J Agric Food Chem 2005; 53: 4740-4746

[25] Dominguez-Avila JA, Wall-Medrano A, Velderrain-Rodriguez GR, Chen CO, Salazar-Lopez NJ, Robles-Sanchez M, Gonzalez-Aguilar GA. Gastrointestinal interactions, absorption, splanchnic metabolism and pharmacokinetics of orally ingested phenolic compounds. Food Funct 2017; 8: $15-38$

[26] Stelmakiene A, Ramanauskiene K, Briedis V. Release of rosmarinic acid from semisolid formulations and its penetration through human skin ex vivo. Acta Pharm 2015; 65: 199-205

[27] Wüst Zibetti A, Aydi A, Claumann CA, Eladeb A, Adberraba M. Correlation of solubility and prediction of the mixing properties of rosmarinic acid in different pure solvents and in binary solvent mixtures of ethanol + water and methanol + water from (293.2 to 318.2) K. J Mol Liq 2016; 216: $370-376$

[28] Peng X, Wang X, Qi W, Su R, He Z. Affinity of rosmarinic acid to human serum albumin and its effect on protein conformation stability. Food Chem 2016; 192: 178-187

[29] Shamsi A, Ahmed A, Khan MS, Al Shahwan M, Husain FM, Bano B. Understanding the binding between rosmarinic acid and serum albumin: in vitro and in silico insight. J Mol Liq 2020; 311: 113348

[30] Chen JF, Bao X, Lin C, Zhou G. Pharmacokinetics of rosmarinic acid in rats and tissue distribution in mice. Lat Am J Pharm 2019; 38: 985-990

[31] Zoric Z, Markic J, Pedisic S, Bucevic-Popovic V, Generalic-Mekinic I, Grebenar K, Kulisic-Bilusic T. Stability of rosmarinic acid in aqueous ex- 
tracts from different Lamiaceae species after in vitro digestion with human gastrointestinal enzymes. Food Technol Biotechnol 2016; 54: 97102

[32] Goncalves GA, Correa RCG, Barros L, Dias MI, Calhelha RC, Correa VG, Bracht A, Peralta RM, Ferreira I. Effects of in vitro gastrointestinal digestion and colonic fermentation on a rosemary (Rosmarinus officinalis $\mathrm{L}$ ) extract rich in rosmarinic acid. Food Chem 2019; 271: 393-400

[33] de Torre MP, Vizmanos JL, Cavero RY, Calvo MI. Improvement of antioxidant activity of oregano (Origanum vulgare L.) with an oral pharmaceutical form. Biomed Pharmacother 2020; 129: 110424

[34] Jandhyala SM, Talukdar R, Subramanyam C, Vuyyuru H, Sasikala M, Nageshwar Reddy D. Role of the normal gut microbiota. World J Gastroenterol 2015; 21: 8787-8803

[35] Velderrain-Rodriguez GR, Palafox-Carlos H, Wall-Medrano A, AyalaZavala JF, Chen CY, Robles-Sanchez M, Astiazaran-Garcia H, AlvarezParrilla E, Gonzalez-Aguilar GA. Phenolic compounds: their journey after intake. Food Funct 2014; 5: 189-197

[36] Konishi Y, Kobayashi S. Transepithelial transport of rosmarinic acid in intestinal Caco-2 cell monolayers. Biosci Biotechnol Biochem 2005; 69: 583-591

[37] Bel-Rhlid R, Crespy V, Page-Zoerkler N, Nagy K, Raab T, Hansen CE. Hydrolysis of rosmarinic acid from rosemary extract with esterases and Lactobacillus johnsonii in vitro and in a gastrointestinal model. J Agric Food Chem 2009; 57: 7700-7705

[38] Mosele JI, Martin-Pelaez S, Macia A, Farras M, Valls RM, Catalan U, Motilva MJ. Study of the catabolism of thyme phenols combining in vitro fermentation and human intervention. J Agric Food Chem 2014; 62: 10954-10961

[39] Nakazawa T, Ohsawa K. Metabolism of rosmarinic acid in rats. J Nat Prod 1998; 61: 993-996

[40] Nakazawa T, Ohsawa K. Metabolites of orally administered Perilla frutescens extract in rats and humans. Biol Pharm Bull 2000; 23: 122-127

[41] Baba S, Osakabe N, Natsume M, Terao J. Orally administered rosmarinic acid is present as the conjugated and/or methylated forms in plasma, and is degraded and metabolized to conjugated forms of caffeic acid, ferulic acid and m-coumaric acid. Life Sci 2004; 75: 165-178

[42] Achour M, Saguem S, Sarria B, Bravo L, Mateos R. Bioavailability and metabolism of rosemary infusion polyphenols using Caco-2 and HepG2 cell model systems. J Sci Food Agric 2018; 98: 3741-3751

[43] Su J, Jia F, Lu J, Chen W, Sun H, Liu T, Wu X. Characterization of the metabolites of rosmarinic acid in human liver microsomes using liquid chromatography combined with electrospray ionization tandem mass spectrometry. Biomed Chromatogr 2020; 34: e4806

[44] Baba S, Osakabe N, Natsume M, Yasuda A, Muto Y, Hiyoshi K, Takano H, Yoshikawa T, Terao J. Absorption, metabolism, degradation and urinary excretion of rosmarinic acid after intake of Perilla frutescens extract in humans. Eur J Nutr 2005; 44: 1-9

[45] Noguchi-Shinohara M, Ono K, Hamaguchi T, Iwasa K, Nagai T, Kobayashi S, Nakamura H, Yamada M. Pharmacokinetics, safety and tolerability of Melissa officinalis extract which contained rosmarinic acid in healthy individuals: a randomized controlled trial. PLoS One 2015; 10: e0126422

[46] Nieman KM, Sanoshy KD, Bresciani L, Schild AL, Kelley K, Lawless A, Ceddia MA, Maki KC, Del Rio D, Herrlinger KA. Tolerance, bioavailability, and potential cognitive health implications of a distinct aqueous spearmint extract. Funct Food Health Dis 2015; 5: 165-187

[47] Nurmi A, Nurmi T, Mursu J, Hiltunen R, Voutilainen S. Ingestion of oregano extract increases excretion of urinary phenolic metabolites in humans. J Agric Food Chem 2006; 54: 6916-6923

[48] Zhang J, Wen Q, Qian K, Feng Y, Luo Y, Tan T. Metabolic profile of rosmarinic acid from Java tea (Orthosiphon stamineus) by ultra-high-performance liquid chromatography coupled to quadrupole-time-of-flight tandem mass spectrometry with a three-step data mining strategy. Biomed Chromatogr 2019; 33: e4599
[49] Nadeem M, Imran M, Gondal TA, Imran A, Shahbaz M, Amir RM, Sajid MW, Qaisrani TB, Atif M, Hussain G, Salehi B, Ostrander EA, Martorell M, Sharifi-Rad J, Cho WC, Martins N. Therapeutic potential of rosmarinic acid: a comprehensive review. Appl Sci 2019; 9: 3139

[50] Elufioye TO, Habtemariam S. Hepatoprotective effects of rosmarinic acid: Insight into its mechanisms of action. Biomed Pharmacother 2019; 112: 108600

[51] Alagawany M, Abd El-Hack ME, Farag MR, Gopi M, Karthik K, Malik YS, Dhama K. Rosmarinic acid: modes of action, medicinal values and health benefits. Anim Health Res Rev 2017; 18: 167-176

[52] Bekut M, Brkic S, Kladar N, Dragovic G, Gavaric N, Bozin B. Potential of selected Lamiaceae plants in anti(retro)viral therapy. Pharmacol Res 2018; 133: 301-314

[53] Connelly AE, Tucker A], Tulk H, Catapang M, Chapman L, Sheikh N, Yurchenko S, Fletcher R, Kott LS, Duncan AM, Wright AJ. High-rosmarinic acid spearmint tea in the management of knee osteoarthritis symptoms. J Med Food 2014; 17: 1361-1367

[54] Falcone PH, Tribby AC, Vogel RM, Joy JM, Moon JR, Slayton CA, Henigman MM, Lasrado JA, Lewis BJ, Fonseca BA, Nieman KM, Herrlinger KA. Efficacy of a nootropic spearmint extract on reactive agility: a randomized, double-blind, placebo-controlled, parallel trial. J Int Soc Sports Nutr 2018; 15: 58

[55] Herrlinger KA, Nieman KM, Sanoshy KD, Fonseca BA, Lasrado JA, Schild AL, Maki KC, Wesnes KA, Ceddia MA. Spearmint Extract improves working memory in men and women with age-associated memory impairment. J Altern Complement Med 2018; 24: 37-47

[56] Scholey A, Gibbs A, Neale C, Perry N, Ossoukhova A, Bilog V, Kras M, Scholz C, Sass M, Buchwald-Werner S. Anti-stress effects of lemon balm-containing foods. Nutrients 2014; 6: 4805-4821

[57] Lee J, Jung E, Koh J, Kim YS, Park D. Effect of rosmarinic acid on atopic dermatitis. J Dermatol 2008; 35: 768-771

[58] Osakabe N, Takano H, Sanbongi C, Yasuda A, Yanagisawa R, Inoue K, Yoshikawa T. Anti-inflammatory and anti-allergic effect of rosmarinic acid (RA); inhibition of seasonal allergic rhinoconjunctivitis (SAR) and its mechanism. Biofactors 2004; 21: 127-131

[59] Takano H, Osakabe N, Sanbongi C, Yanagisawa R, Inoue K, Yasuda A, Natsume M, Baba S, Ichiishi E, Yoshikawa T. Extract of Perilla frutescens enriched for rosmarinic acid, a polyphenolic phytochemical, inhibits seasonal allergic rhinoconjunctivitis in humans. Exp Biol Med (Maywood) 2004; 229: 247-254

[60] Alam MA, Subhan N, Hossain H, Hossain M, Reza HM, Rahman MM, Ullah MO. Hydroxycinnamic acid derivatives: a potential class of natural compounds for the management of lipid metabolism and obesity. Nutr Metab (Lond) 2016; 13: 27

[61] Fazli D, Malekirad AA, Pilevarian AA, Salehi H, Zeraatpishe A, Rahzani K. Abdollahi M. Effects of Melissa officinalis L. on oxidative status and biochemical parameters in occupationally exposed workers to aluminum: a before after Clinical Trial. Int J Pharmacol 2012; 8: 455-458

[62] Nayebi N, Esteghamati A, Meysamie A, Khalili N, Kamalinejad M, Emtiazy M, Hashempur MH. The effects of a Melissa officinalis L. based product on metabolic parameters in patients with type 2 diabetes mellitus: a randomized double-blinded controlled clinical trial. I Complement Integr Med 2019. doi:10.1515/jcim-2018-0088

[63] Javid AZ, Haybar H, Dehghan P, Haghighizadeh MH, Mohaghegh SM, Ravanbakhsh M, Mohammadzadeh A. The effects of Melissa officinalis (lemon balm) in chronic stable angina on serum biomarkers of oxidative stress, inflammation and lipid profile. Asia Pac J Clin Nutr 2018; 27: 785791

[64] Asadi A, Shidfar F, Safari M, Malek M, Hosseini AF, Rezazadeh S, Rajab A, Shidfar S, Hosseini S. Safety and efficacy of Melissa officinalis (lemon balm) on ApoA-I, Apo B, lipid ratio and ICAM-1 in type 2 diabetes patients: a randomized, double-blinded clinical trial. Complement Ther Med 2018; 40: 83-88 
[65] Jun H], Lee JH, Jia Y, Hoang MH, Byun H, Kim KH, Lee S]. Melissa officinalis essential oil reduces plasma triglycerides in human apolipoprotein E2 transgenic mice by inhibiting sterol regulatory element-binding protein-1c-dependent fatty acid synthesis. J Nutr 2012; 142: 432-440

[66] Madureira AR, Campos D, Gullon B, Marques C, Rodriguez-Alcala LM, Calhau C, Alonso JL, Sarmento B, Gomes AM, Pintado M. Fermentation of bioactive solid lipid nanoparticles by human gut microflora. Food Funct 2016; 7: 516-529

[67] Madureira AR, Campos DA, Oliveira A, Sarmento B, Pintado MM, Gomes AM. Insights into the protective role of solid lipid nanoparticles on rosmarinic acid bioactivity during exposure to simulated gastrointestinal conditions. Colloids Surf B Biointerfaces 2016; 139: 277-284

[68] Baranauskaite J, Duman G, Corapcioglu G, Baranauskas A, Taralp A, Ivanauskas L, Bernatoniene J. Liposomal incorporation to improve disso- lution and stability of rosmarinic acid and carvacrol extracted from oregano (O. onites L.). Biomed Res Int 2018; 2018: 6147315

[69] Shakeri A, Sahebkar A, Javadi B. Melissa officinalis L.-a review of its traditional uses, phytochemistry and pharmacology. J Ethnopharmacol 2016; 188: $204-228$

[70] Li S, Xie X, Li D, Yu Z, Tong L, Zhao Y. Simultaneous determination and tissue distribution studies of four phenolic acids in rat tissue by UFLC-MS/MS after intravenous administration of salvianolic acid for injection. Biomed Chromatogr 2018; 32: e4128

[71] Li X, Yu C, Lu Y, Gu Y, Lu J, Xu W, Xuan L, Wang Y. Pharmacokinetics, tissue distribution, metabolism, and excretion of depside salts from Salvia miltiorrhiza in rats. Drug Metab Dispos 2007; 35: 234-239 